\title{
The Elimination of Waste in Higher Education: Prescriptions for Doing the Right Things the Right Way
}

\author{
Michael Hayden \\ Email: michael.hayden@indstate.edu \\ Randy Peters \\ Email: randy.peters@indstate.edu
}

Indiana State University

\begin{abstract}
Purpose: The authors defined waste in higher education and describe proven strategies to reduce waste, from and engineering and technical background, informed by $\mathrm{HE}$ administrative perspectives. It is important to categorize waste and then prioritize it because effort should be spent on eliminating the waste that has the greatest potential to improve the efficiency of the entire system. Waste can only be dealt with by someone with the span of control over that waste.

Design/Methodologies/Approach: This paper is based upon on a case study approach of the authors own department and university, based upon own subject matter expertise.

Findings: The authors describe how functions have been streamlined so that the department faculty can generate twice as many student credit hours per faculty member, improve retention and graduation rates, and improve accreditation results - without increasing faculty work load. allowing the faculty to spend more time on scholarship and service.

Practical Implications: This study contributes to LSS principles based in higher education but also provides information and prescriptions for the faculty today, but preparing future faculty tomorrow.
\end{abstract}

Originality: This study contributes to the literature through an SME approach on how faculty may navigate the higher education environment through the examples provided in this case.

Keywords: Case study, Lean, Higher Education

Paper type: Conference 


\section{Introduction}

The reason for this paper is that we, the authors, see colleagues unhappy at work. It seemed to us that the faculty is often treated as an unlimited resource for administrators, staff, and students to task as they see fit. The result is that some of our colleagues did not seem content but harried; they were not energized by their faculty role but resigned to it. The focus of this paper is to share proven practices to help the individual faculty member or administrator perform their core tasks (hit the target) in the most efficient manner.

Quality techniques encompassed by Six Sigma are very useful in choosing the target and hitting it consistently. Lean techniques are very useful in hitting those targets with the most ease and least effort. Department leadership, e.g., the department chair and senior faculty members, can facilitate their colleagues to improve quality and efficiency. Mostly based on our own experiences, we are going to summarize Lean and Six Sigma (LSS) practices that have aided faculty members in productively and contently fulfilling their roles. We are going to outline how administrators can help themselves and faculty members be more efficient and have higher quality.

\section{Review}

\subsection{LSS}

Quality as a noun means characteristic. There are only going to be some characteristics (targets) of primary importance. Efficiency is more than fast or cheap. Time and money, like other resources, should not be squandered. Nor should there be a squandering or diminishing of human talent, safety, and general well-being. To only focus on doing things faster or cheaper can lead to (a) missing the target or hitting it less consistently and (b) doing some things the right way but not others. Speeding up or saving money on one part of a system can slow down and increase the cost of the entire system.

\subsection{Efficiency}

Lean is a view of efficiency that focuses on work vs waste. See Figure 1. In practice, it is common to focus on the waste part of equation; the less waste, the leaner the work. However, you can also raise efficiency by doing more work.

Figure 1. Efficiency Formula

$$
\text { Efficiency }=\frac{\text { Work }}{\text { Waste }}
$$

Work vs waste. In the context of LSS, work does not merely refer to activity or accomplishment. "Work" means adding customer-desired value. "Waste" is whatever is not work. See figure 2 below. 
Figure 2. Partitioning of Work and Waste

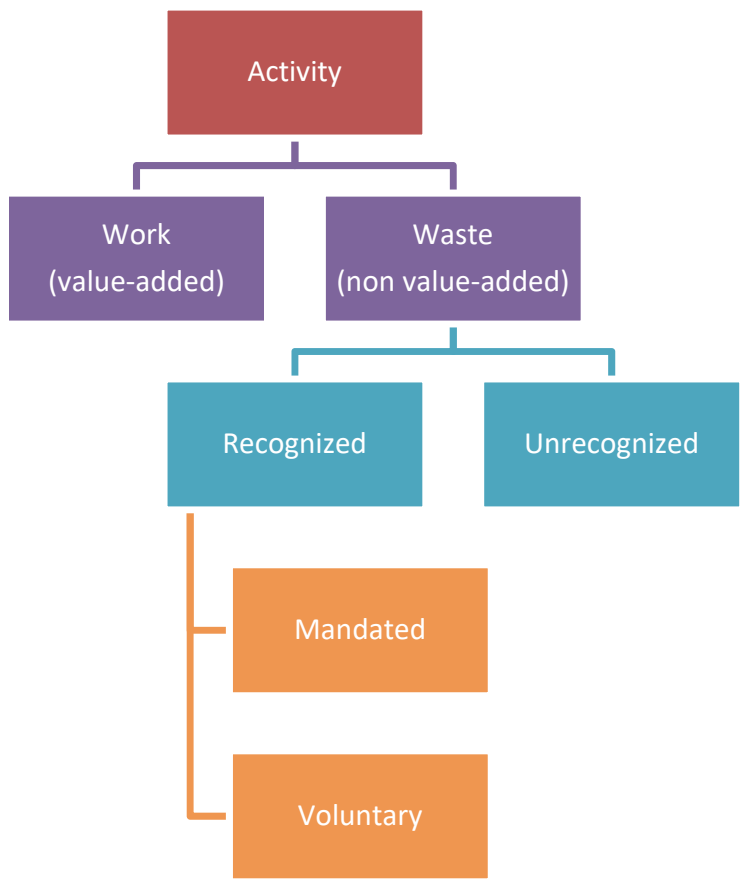

\section{Review - Prescriptions}

\subsection{Prescription 1 - Know the Basics}

Many organizational conditions need to exist before any level of quality and efficiency can be sought; good management and leadership are primary among those conditions. An organization needs a clear vision and mission, organizational chart, and job descriptions to function as an organization. The targets must be defined and understood. The value streams to the targets must be understood. Knowing your wastes is prerequisite to reducing them.

Having too many priorities is a detriment to an organization. Something should not be a target unless it directly related to a accomplishing the core mission of the organization. An organization that continually expands their mission, organizational structure, managers and staff, or procedures and rules is headed away from quality and efficiency. It is an organizational effectiveness prerequisite that the person assigned a task is (a) knowledgeable of how to accomplish the task and (b) has the authority and resources to accomplish the task.

\subsection{Prescription 2 - Believe the Basics}

True believers are required to accomplish all that is possible with LSS. You can convert some people with bribes or pep talks but believers stay believers only when they see the results. You can create true believers by believing it yourself and showing the results of applying LSS.

\subsection{Prescription 3 - Apply the Basics}

Success may not be guaranteed, but you cannot get a new thing with the old behavior. The basics include not only all the LSS tools, but also the tools of management and other disciplines. Via 
cost-benefit, risk, Pareto, and other analyses, decisions need to be made. Fast-paced decision making and fast-paced problem solving need to be the norm. Such alacrity is often not part of a university's culture.

\subsection{Prescription 4 - Learn to Say No; Do Not Bite Off What You Are Not Supposed to Chew} Proper organizational charts and job descriptions work for a reason; they clarify who is supposed to do what and conversely who should not be doing it. You can't do the best at what you are supposed to do if you are doing things you do not need to do.

\subsection{Prescription 5 - Do Not Bite Off What You Cannot Chew}

Sometimes the knowledgeable believer does not have the authority or resources to do what they want to do or have been assigned to do. A common problem we see is that faculty members are often expected to accomplish things for which they have no time, ability, authority, or budget to accomplish.

\section{Case Study}

\subsection{Problem Gap}

Though we have a penchant for quality and efficiency, our impetus for getting serious about waste was our realization that there was a large gap between what we were expected to do and what we could do.

Within about a five-year period the following happened to our department.

- The SCH/faculty member doubled.

- The proportion of distance students, international students, and non-traditional students increased.

- The variation in the preparedness of our students increased.

- The university adopted about a dozen new software platforms.

- A doubling of tasks related to university initiatives.

- A doubling of the duties the department chair.

\subsection{Solutions}

Born of necessity, if not desperation, we decided to practice what we preach. Collectively, our department faculty members are experts in many management practices and in engineering and technical education. At least for the work and waste under our span of control, we could change things - if we wanted to.

\subsection{Defining Our Wastes}

At the beginning of the process the conventional wisdom was that we had little waste. We needed to differentiate activity and work so we honestly partitioned the bulk of activities according to Figure 2. Our realistic focus was the voluntary wastes. In short, we applied LSS tools to recognize, prioritize, and reduce voluntary wastes.

\subsection{Saying No, That's Not My Job}

We realized that we had a lot of unrecognized waste. Gradually we repartitioned many of our activities to the waste categories. We carefully looked at the assumed mandated wastes because 
there was a tendency to label all waste as mandated, therefore, we could do nothing about it, so why bother. When we defined mandated as "there is a high probability that I will lose my job if I do not do this activity" we were able to move much of the mandated wasted to the voluntary waste category.

\subsection{Saying No, That's Not Important}

We prioritized the work and waste issues over which we had control. The department chair focused on his span of control for department-wide issues. The senior faculty member focused on his own quality and efficiency and then shared those practices with other faculty members. We freed up time to do more work by ignoring things that we did not have to do. We applied DMAIC to many things, e.g., outcomes assessment, program review, and accreditation. We streamlined and clarified who had to do what and when it had to be done. We significantly reduced the denominator of the efficiency formula.

\subsection{More Work, Not Just Less Waste}

We also increased the numerator of the efficiency formula by simplifying, standardizing, and documenting department procedures and policies that clarified tasks and assigned the needed authority and resources to complete those tasks. We simplified curriculum by moving all programs to ABET and creating a curriculum core. We standardized syllabi. We developed very clear promotion, tenure, and performance review standards that clarified teaching, scholarship, and service expectations. We created several policies that encourage or require best practices regarding evaluating student work, dealing with absences, and encouraging student involvement in professional organizations and preparation for professional exams.

\subsection{Creating Converts}

While a few of our best practices have been adopted by other departments, most of our quality and efficiency achievements are being accomplish at the department and faculty member level. We have converted many colleagues by accomplishing the same or more than them but spending half the time to accomplish it.

\subsection{Current State}

Thus far, the fruit of our labors is that we have met all the previously bulleted challenges while increasing quality and efficiency (as measured by internal metrics and according to the results of outcomes assessment, accreditation, and students' scores on professional exams). We are at the top of many internal metrics.

\section{Conclusion}

One of the biggest obstacles to improving quality and efficiency is inattention. Faculty members and administrators can be unaware of the gap between the current state of things and the possible state. Even when the needed resources are present, no problem can be solved without it first being identified. No problem can be identified without the ability and will to define the gap between what is and what should be.

\section{Lessons Relearned}

We relearned several things that are now out of vogue, chief among them were the following:

- Management practices are responsible for quality and efficiency (and the lack thereof). Deming was right about every one of his points and diseases. 
- Classical management is key, e.g., a clear mission, division of labor, and proper scheduling and assigning of tasks. It is a quality and productivity killer to try to be all things to all people, to have too many tasks, and to expect everyone to complete every task. When faculty members are treated as on infinite resource, quality and efficiency are reduced.

- Methodically applied, proven practices based on logic and facts are best. Frederick Taylor was correct about his scientific principles of management.

- Regardless of what is stated, the real mission is whatever is rewarded.

- Regardless of what is stated, the only person who can accomplish a task is the one with the authority and resources to do so.

- Change is only good when others like the result. The best way to convert others is for them to see the benefits of your way of doing things.

- Our prescriptions (or something like them) needed to be fulfilled to enable real improvement in quality and efficiency. 